\title{
O CORPO EM CIRCUNSTÂNCIA: UMA COMPREENSÃO FENOMENOLÓGICA DA NUDEZ NAS PERFORMANCES DE REGINA JOSÉ GALINDO
}

\author{
THE BODY IN CIRCUMSTANCE: \\ A PHENOMENOLOGICAL UNDERSTANDING OF THE NUDE IN \\ THE PERFORMANCES OF REGINA JOSÉ GALINDO \\ EL CUERPO EN CIRCUNSTANCIA: \\ UNA COMPRENSIÓN FENOMENOLÓGICA DE LA DESNUDEZ \\ EN LAS PERFORMANCES DE REGINA JOSÉ GALINDO
}

\author{
Stephanie Ares Maldonado \\ Graduanda na Faculdade de Ciências Aplicadas (FCA), \\ Universidade Estadual de Campinas (Unicamp) \\ stephanie118691@gmail.com \\ Eduardo Marandola Jr. \\ Professor na Faculdade de Ciências Aplicadas (FCA), \\ Universidade Estadual de Campinas (Unicamp) \\ eduardo.marandola@fca.unicamp.br
}

\begin{abstract}
Resumo: A possibilidade do fazer artístico se dá na relação artista-lugar, mesmo se esta relação for composta por tensôes existenciais e conflitos ideológico-culturais. Sem esse corpo posto em circunstancialidade, como poderia a obra de arte existir, ser apresentada e apreciada? Esse aspecto, muito evidente nas performances que Regina José Galindo apresenta nua, mostra que mesmo a arte crítica emana dessa associação essencial entre o corpo senciente-sensível do artista com o mundo que coabita com os corpos associados expectadores de sua obra. Nesse contexto, a base existencial, que circunscreve as experiências criativas e expressivas de Galindo e que pôde ser acessada em nossa mundanidade comum, acabou por resultar neste artigo.
\end{abstract}

Palavras-chave: Lugar; Arte; Feminino; Geografia Humanista; Maurice Merleau-Ponty.

Abstract: The possibility of making art takes place in the relation artist-place, even if that relation comprises existential tensions and ideological-cultural conflicts. Without the body in circumstance, how could the work of art exist, be presented and appreciated? That aspect is evident in Regina José Galindo's naked performances. It shows that even critical art 
emanates from this essential association between the artist's sentient-sensitive body and the world, cohabited with associated bodies which view her work. In this context, the existential basis, that circumscribes Galindo's creative and expressive experiences and that could be accessed in our shared worldliness, eventually resulted in this article.

Keywords: Place; Art; Feminine; Humanistic Geography; Maurice Merleau-Ponty.

Resumen: La posibilidad del hacer artístico se da en en la relación artista-lugar, incluso si esta relación es compuesta por tensiones existenciales y conflictos ideológicos-culturales. ¿Sin ese cuerpo puesto en circunstancialidad, como podría la obra de arte existir, ser presentada (exhibida) y apreciada? Ese aspecto, tan evidente en las performances que Regina José Galindo se presenta desnuda, muestra que incluso el arte crítico emana de esa asociación esencial entre el cuerpo sentiente-sensible del artista con el mundo que cohabita con los cuerpos asociados espectadores de su obra. En este contexto, la base existencial, que circunscribe las experiencias creativas y expresivas de Galindo y que puede ser accedida en nuestra mundanidad, tuvo como resultado este artículo.

Palabras clave: Lugar; Arte; Femenino; Geografía Humanista; Maurice Merleau -Ponty.

\section{INTRODUÇÃO}

Que pode um corpo no lugar?

Esta pergunta remete à pequenez do corpo, sua delicadeza e efemeridade, sobretudo quando consideramos os grandes espaços, os grandes eventos, a imensidão do mundo.

Um corpo parece não oferecer nada: mero receptáculo, transeunte em um mundo cheio de coisas. Nem para preencher um lugar ele se dá.

Que pode um corpo em um país?

Se no lugar, de escala variável, o corpo talvez não impressione, que dizer no país? Pequeno, temporário, frágil, fugaz. Um corpo não contém um país.

Mas, como nos ajuda a pensar a fenomenologia de Maurice Merleau-Ponty, a partir do "duplo encontro" do mundo e do corpo (LEFORT, 2013, p.10), compreendemos que o corpo "não é a junção de suas partes às outras", nem carcaça que encobre nossa psique e alma (MERLEAU-PONTY, 2013, pp. 20-21). O corpo, para o filósofo, é o que somos, vivemos, tomamos consciência do mundo e, no qual, nos relacionamos com os outros. Trata-se de um corpo multidimensional, que é ao mesmo tempo perceptivo, sexual, individual, sentimental, histórico, psíquico, místico e "socialmente situado" (MERLEAUPONTY, 2011, p. 600).

Esta compreensão do corpo nos permite responder, portanto, de outra forma à pergunta: “Que pode o corpo no lugar?”. Nem receptáculo, nem preenchimento, o corpo no lugar é a própria ontologia existencial manifestada, presentificada ou, para usar uma expressão merleau-pontyana, encarnada (MERLEAU-PONTY, 2007). Isso significa que é tocante e tocado, sentido e sensível, visível e visualizador. Em termos geográficos, é lugar e ser. 
Revela-se assim a potência ontológica geográfica do corpo, nosso foco de interesse. Buscamos pensá-la por meio da manifestação artística, especificamente, sobre a força do corpo nu na obra performática de Regina José Galindo, ${ }^{1}$ artista guatemalense conhecida pela sua maneira sensível e inovadora de abordar os temas mais delicados e traumáticos, como a violência contra a mulher e tantos outros abusos decorrentes das discrepâncias de poderes nas relaçóes sociais.

Seu fazer artístico que ressignifica a relação corpo-lugar é nossa motivação, buscando pensar na força do corpo nu como expressividade e política, no esforço de dar visibilidade às intencionalidades (MERLEAU-PONTY, 2011, p. 16) que ligam Galindo (corpo e obra) ao mundo vivido (lugar): a Guatemala, a América Latina e, sobremaneira, seu Corpo Feminino.

\section{GUATEMALA ANUNCIADA: ESTILO ARTÍSTICO E CORPO FEMININO}

A geógrafa Lívia de Oliveira (2014), pensando no "sentido do sentido" optou em usar sentido como "o que as coisas querem dizer" (OLIVEIRA, 2014, pp. 5-6). Pegando de empréstimo essa ideia, o que a nudez nas performances de Galindo quer dizer?

Figura 1 - "Piel” (Foto de Anibal López)

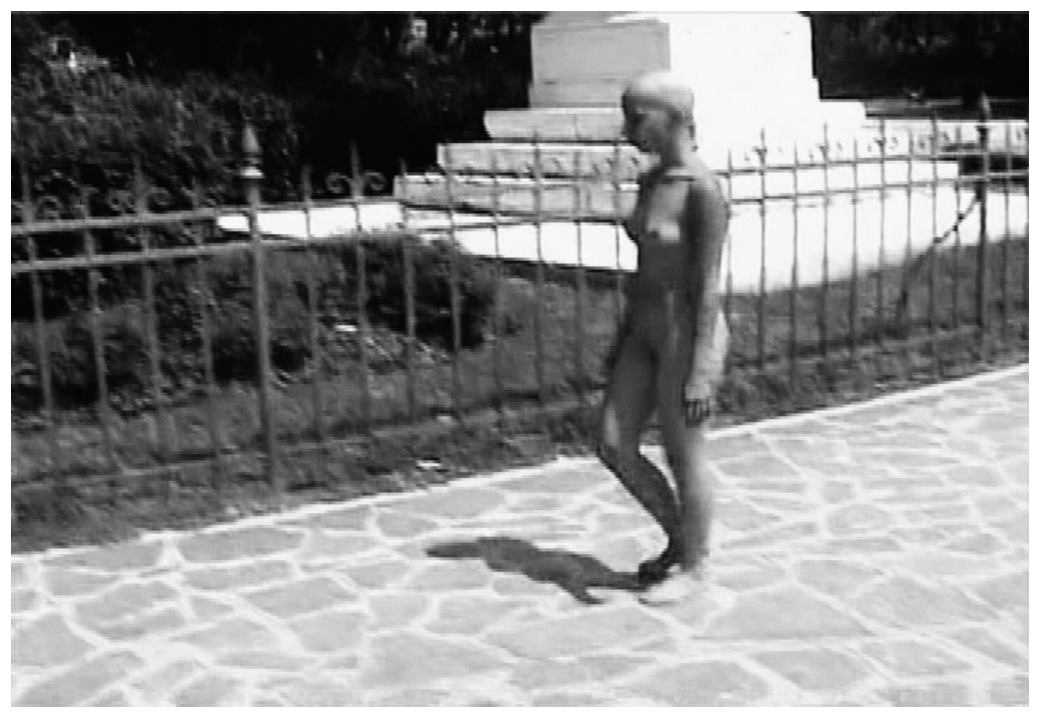

Fonte - Portfólio online da artista (2016)

Na performance "Piel”2 (Itália/2001), Galindo assume que o propósito de caminhar

\footnotetext{
$1 \quad$ Regina José Galindo nasceu em 1974 na Cidade da Guatemala, onde segue vivendo, apesar de frequentemente se apresentar em outros países, como na Itália. Em seu site oficial, sua obra é resumida em um trabalho que "explora as implicaçōes éticas universais das injustiças sociais, relacionadas com discriminaçóes raciais, de gênero e outros abusos decorrentes das desiguais relaçóes de poder que funcionam na nossa sociedade atual” (GALINDO, 2017, p. 1, tradução livre).

2 Tradução livre: "Pé".
} 
sem nenhuma "protección" (sem roupas e com os cabelos e pelos raspados) era de mostrar "la vulnerabilidad del cuerpo latino-americano" (GALINDO, 2014a). Caminhando nua e em "silêncio" (CASALINI, 2013) pelas ruas de Veneza, ela solicita nosso olhar para essa aura de fragilidade e fraqueza, constituída naquele momento pelo seu próprio "sentir" (MERLEAU-PONTY, 2013, p. 77).

Esse silêncio somado à nudez, muito presentes na obra de Galindo, formam uma atmosfera tensa e inquietante. Em primeiro lugar, o silêncio fala ao seu modo, porque nele ainda algo é exprimido (MERLEAU-PONTY, 2014). Giulia Casalini, dedicandose ao estudo da técnica de Galindo, já havia se debruçado sob a diferença entre o silêncio e o ato de ficar quieto. Ela nos explica que o silêncio é uma condiçáo técnica ou social e ficar quieto é a recusa de realizar uma ação onde o silêncio é uma possibilidade. O silêncio então, é um dos principais meios que a artista encontrou de invocar o sofrimento (CASALINI, 2013) presente no fundo invisível que a move ao fazer artístico.

Mas e a nudez? Ela também compõe de forma incomensurável o estilo da artista. Se é ela que logo nos faz rejeitar, estranhar, recusar ou, pelo menos, indagar a obra de Galindo é porque há nessa nudez artística uma potência manifestada. Potência dada ao ponto que a artista nos escancara esse corpo sensível que incessantemente vem sendo afastado e esquecido. O que, a primeira mão, pode parecer um carácter exibicionista da artista é, na verdade, um meio de provocação necessária para que sua arte transgrida o lugar, nos remetendo para experiências de sofrimento que a afetam, mas que são, ao mesmo tempo, além-Galindo.

O estilo de um artista, esse "sistema de equivalências que ele se constitui para essa obra de manifestação, o índice universal da deformação coerente pela qual concentra o sentido ainda esparso em sua percepção e o faz existir expressamente" é o que faz resultar uma estética que é, justamente, a novidade proporcionada pelo artista, permitindo-o passar para a obra o mundo que vê, à sua própria linguagem, expressando o "seu encontro com o mundo" (MERLEAU-PONTY, 2013, pp. 81-83).

É possível ainda dizer que o estilo de Galindo, partindo de sua experiência do mundo, bebe de tudo que ela é, historicamente, politicamente, socialmente, culturalmente e de qualquer outro recorte possível nesse sentido. Porém, sua obra não é uma junção objetiva desses aspectos, nem a mescla perfeita de cada um deles, porque arte é dar vida a percepções por vezes não racionalizadas, é criação expressiva, ela não se permite ser "a tradução de um pensamento já claro, pois os pensamentos já claros são os que já foram ditos dentro de nós ou pelos outros" e o papel do artista é justamente "invocar uma razão que abarcaria suas próprias origens” (MERLEAU-PONTY, 2013, p.139).

Dessa própria natureza da arte emerge a possibilidade de Galindo afirmar categoricamente que, por mais que ela tenha como indivíduo posiçôes políticas muito claras, suas performances não são um protesto político, mas são puramente arte (GALINDO,

Tradução livre: "proteção".

Tradução livre: "a vulnerabilidade do corpo latino-americano". 
2014a). Isso não demonstra nenhuma ambiguidade entre o modo de Galindo se colocar no mundo e o seu fazer artístico. Enquanto corpos, somos dotados de múltiplas maneiras de nos mostrarmos aos outros, e os artistas, em especial, são capazes de se expressarem para além dos moldes habituais, apontando outros modos de se enfrentar a vida, em qualquer uma de suas esferas. Essa diferença, portanto, se marca na obra de Galindo através desses dois elementos (o silêncio e a nudez) que, incorporados no fazer artístico, rompem coma cotidianidade.

Segundo os depoimentos sobre a vida artística de Balzac (escritor francês do século XIX) e Cézanne (pintor francês do século XX), trazidos à luz por Merleau-Ponty, revela-se que o artista "não se contenta em ser um animal cultivado, ele assume a cultura desde seu começo e funda-a novamente" (MERLEAU-PONTY, 2013, p.139). É essencial para um artista viver, agir e criar para fora do comum, do banal, do usual. Mas, mesmo nessa visão, a arte ainda se mostra como conhecimento circunstancialmente expressado, fadado ao lugar, porque a criação artística, ou até mesmo a crítica política, por exemplo, ainda dependem do indivíduo assumir seu lugar no tecido do mundo e vivê-lo, abarcando-o e enfrentando-o a todo momento.

Em suma, a existência de Galindo, sua maneira de habitar o mundo e de fazer arte devem à Guatemala. Não é uma determinação, mas uma fundação que reverbera. Seus traços, sua hereditariedade, seus hábitos, sua fisionomia, seu feminino, seu jeito de olhar e caminhar, suas histórias e memórias coletivamente construídas. Ou ainda, mais especificamente, tudo que a nudez nos escancara e que as roupas podem esconder, sendo cicatrizes, partes do corpo que costumeiramente reservamos às intimidades (como órgáos sexuais, nádegas e, principalmente no caso da mulher, seios) e determinadas marcas culturais e sociais (como tatuagens).

A Guatemala está incrustada no corpo de Galindo, não como fator determinístico, mas como fundamento que impossibilita discernir onde começa Guatemala e acaba Galindo, ou vice-versa, porque para sempre será "Galindo: mulher e artista guatemalense". Assim, seus expectadores, ao terem a oportunidade de experienciar a obra de Galindo, conseguem ainda aspirar Guatemala, já que "a constituição do lugar e do eu são indissociáveis, pois têm os mesmos processos constitutivos, operando nos dois polos: eu-lugar" (MARANDOLA JR., 2014, p. 244).

A potência da performance artística está na sua capacidade de aproximar, em um só momento e espaço "o corpo do artista, a obra e o público" (BIRIBA apud SANTOS, 2008, p. 4). Os elementos do estilo de Galindo atuam criando uma abertura para a "linguagem tácita" com o expectador, onde se transita entre as partes uma "espécie de história por contato". Sendo assim, Galindo pode anteriormente idealizar suas performances, mas elas só se concretizam e ganham sentido na coexistência com os expectadores, não tão passivos quanto a palavra sugere. Afinal, "é nos outros que a expressão adquire relevo e se torna verdadeiramente significação” (MERLEAU-PONTY, 2013, pp. 42-78). Nesse entendimento, vamos bastante de encontro à afirmação feita pela dramaturga Sílvia Fernandes de que "performance nunca é um objeto ou uma obra acabada, mas sempre um processo" (FERNANDES, 2011, p.16). 
Trazendo para os nossos termos, os sentidos das performances artísticas emergem das circunstancialidades dos lugares, pois não estando nem presos ao artista e nem só aos espectadores, eles se formam na relação entre ambos, possibilitada pelos lugares: "a expressão vai de homem para homem através do mundo comum que vivem" e por lugares todos nós vivemos (MERLEAU-PONTY, 2013, p.76).

$\mathrm{Na}$ trajetória artística de Galindo, cada lugar ofereceu aberturas ou tensóes para o seu fazer artístico. Em sua carreira como poetisa, muito mais precoce do que como artista visual, o primeiro contato com a escrita artística foi dado ainda na infância. $\mathrm{O}$ incentivo inicial foi um diário que ganhou de seus pais durante o seu primeiro período menstrual. O que começou como anotaçóes de suas percepçóes diárias, logo se transformou em textos mais elaborados e, posteriormente, em poesia. Enquanto poetisa/ escritora, Galindo obteve não apenas apoio em seu lar, um dos lugares afetivos mais expressivos na constituição do indivíduo, mas também de colegas e amigos que trabalhavam na mesma área. Assim, não enfrentou grandes dificuldades para publicar suas produções nos mais diversos meios de comunicação escrita da Guatemala (GALINDO, 2013, p. 205).

Parece-nos importante salientar essa ligaçáo de Galindo ao feminino desde seu início nas artes. Não só pelo simbolismo que adquire o fato de seu primeiro incentivo à escrita criativa ter sido dado durante sua primeira menstruação, mas pelo próprio estofo de sua arte literária e também de sua arte visual: o sofrimento guatemalense, especialmente para as mulheres, herdado culturalmente e socialmente dos moldes da guerra civil (1960-1996) guatemalense (CASALINI, 2013).

Nascida em meio à guerra (1974), Galindo experienciou o conflito e suas consequências de forma muito próxima, o que certamente influenciou o seu fazer artístico (GALINDO, 2013, p. 205). Ou seja, mesmo quando mais para frente Galindo começou a performar o sofrimento de não-guatemalenses, seu olhar ainda emergia de sua experiência e visão guatemalense.

Mas seria por esta aproximação de conteúdo existencial a recepção de sua obra performática táo positiva quanto a de sua obra literária?

Foquemos em seu primeiro trabalho performático, intitulado "Lo voy a gritar al viento" 5 e apresentado em 1999, onde a artista se pendurou no arco de Edificio de Correos y Telégrafos, 6 na Cidade da Guatemala, e leu seus poemas ao ar (GALINDO, 2017). Aqui, mesmo performando, ainda havia bastante aproximação entre as duas formas de arte, pois a artista, ainda vestida, concentrou-se em apenas declarar seus poemas. Nesse ato, aparentemente ingênuo, Galindo provocava seu público a repensar seus conceitos de arte e suas concepções culturais, históricas e políticas, dando o primeiro passo para o que sua obra visual viria a se tornar.

Tradução livre: "Eu vou gritar ao vento".

Tradução livre: "arco do Edifício dos Correios e Telégrafos". 
A nudez e o silêncio começam a aparecer como protagonistas de seu estilo na sua segunda performance, "El cielo llora tanto que debería ser mujer" (Guatemala/1999), onde a artista mergulhava nua em uma banheira, prendia a respiração até não poder mais aguentar, retomava o ar e mergulhava novamente. Na sua terceira e última performance do ano de 1999, "El dolor en un pañuelo", ${ }^{8}$ a artista foi amarrada em uma cama vertical e, sob seu corpo nu, se projetavam notícias de violaçóes e abusos cometidos contra as mulheres na Guatemala (GALINDO, 2013; GALINDO, 2014). Aqui, Galindo entra no escopo de mulheres artistas que colocam em suas obras performáticas o próprio corpo nu para transcender "qualquer interesse relacionado a uma arte para chocar táo somente", mas como próprio meio criativo de elucidação dos interesses, das experiências e dos sofrimentos femininos (SANTOS, 2008, p.18).

No ano seguinte, após essas três performances, já se percebe o silêncio vindo abrir espaço para que os outros, os oprimidos, falem. A nudez aparece radicalizando as intençóes da artista, escancarando essa corporeidade da qual nos alienamos. E, mesmo quando vestida, a nudez faz parte desse contexto geral de quem é Galindo enquanto artista, pois a intensidade de sua nudez artística marcou o seu estilo, como uma presença que se dá mesmo na ausência.

Existe na nudez uma potência impactante, assim como na arte (especialmente, na performática). Em Galindo, isso se mostra logo em suas primeiras performances, que causaram escândalo, negaçáo e vergonha para sua família e, de modo geral, para a cidade. Muito diferente da sua experiência como escritora literária e poetisa, acreditou ter seu futuro profissional ameaçado caso continuasse a performar na Guatemala (GALINDO, 2014, GALINDO, 2013).

$\mathrm{O}$ que desavisadamente pode parecer à primeira vista um fracasso de Galindo em lidar com o seu próprio lugar, compóe a sua maestria em performar, sendo que é próprio da arte performática o interesse "na experiência corporal e na ação do artista em situaçóes extremas", pretendendo "desestabilizar o cotidiano por meio da transgressão e da ruptura, promovendo ações artísticas marcadas pela diferença” (FERNANDES, 2011 , p. 16). Tal potência da performance está justamente na corporeidade: o corpo em ação transgride o próprio lugar, transformando-o. Ou seja, a arte performática busca ser mais diretamente provocativa e incisiva do que os outros fazeres artísticos. Com seu estilo já anunciadamente impactante, Galindo intensifica sua provocação ao trazer ao lugar-Guatemala elementos explícitos (e negativos) de sua constituição.

Sendo assim, seu país de origem, fortemente afetado pelo conteúdo da obra de Galindo e ainda distante dos moldes e pretensóes da arte performática e da nudez artística, rejeitara categoricamente suas performances, pelo menos, durante os primeiros dez anos de sua carreira visual. Em lugares como Veneza, onde nunca morou, mas por vezes trabalhou, o contrário: maior abertura para esse tipo de fazer artístico, facilitando a apresentação de performances como "Piel", 9 por exemplo.

\footnotetext{
Tradução livre: "O céu chora tanto que deveria ser mulher".

Tradução livre: "A dor em um pano".

Tradução livre: "Pele".
} 
Ainda que se tenham lugares mais abertos aos fazeres artísticos performáticos do que a Guatemala, como por exemplo Veneza, devemos frisar que o fundo existencial de que fala sua arte não é de fácil acesso à um expectador não-guatemalense, porque conhecer a guerra civil da Guatemala é essencialmente importante para se aprofundar na obra de Galindo. Não que esse seja o único tema de sua obra, mas é expressivo influenciador de todo o seu modo de ver a vida e de fazer arte. Em uma entrevista com Emiliano Valdés, curador do Museu de Arte Moderna de Medeline, Galindo resume seu trabalho:

Trabajo con la intención de reflejar lo que pasa en el mundo, o al menos, lo que sucede en mi contexto. Con cada acción, con cada proyecto deseo generar un diálogo, cuestionar y que el otro también se cuestione. Me interesa investigar las relaciones de poder en todas sus manifestaciones y para ello, recurro a la observación y a la denuncia a través de mi trabajo creativo, y utilizo siempre un discurso simple, pero incisivo ${ }^{10}$ (GALINDO, 2014b).

Sabemos que os lugares são circunscritos diferentemente em cada experiência coletiva ou singular, "pelo espaço existencial e pelas sucessivas conchas ou horizontes de alcance" em que vivem (MARANDOLA JR., 2008, p.106). O que se têm, então, é que mesmo possuindo vivências, culturas ou línguas distintas da artista, todos compartilhamos um mundo com ela, onde todos os lugares se interconectam neste horizonte de sentido que é o mundo. Não que a vida ou os lugares expliquem a obra, mas a vida e a obra se comunicam, se misturam e se confundem. Como nos mostrou Merleau-Ponty (2013, p.141), "essa obra por fazer exigia essa vida".

Portanto, Galindo é capaz de expressar outros lugares que náo "os seus" pois esta própria noção de "lugares seus" é apenas uma expressão imprecisa da constituição intersubjetiva e compartilhada que os lugares são. A capacidade da arte de provocar repercussão e ressonância, como nos lembra Bachelard (2009), ou o assombro e o incômodo, como afirma Schama (2010), é potência de produzir e provocar afetação naquele que frui a arte onde reside sua teleologia, e não em uma expressão de sentido ensimesmada. Assim, a obra de arte obra o mundo, como dizia Heidegger (2012), em um movimento de fundaçáo e repercussão simultâneos.

Neste sentido, qualquer expectador de qualquer nacionalidade fruirá sentidos ao se deparar com as performances de Galindo. Estes não estão apenas na obra em si, mas emergem justamente neste encontro com a arte no mundo. Este mundo, portanto, constitui igualmente a emergência e o sentido da obra de forma renovada a cada fruição.

A nos depararmos com as obras de Galindo, nos engajamos em uma situação que não conseguimos enfrentar e que, todavia, não queremos abandonar. Esse é justamente o conceito de se emocionar que Merleau-Ponty já havia anunciado e que remete diretamente à obra de Galindo. Pois mesmo nos identificando com ela, apreciando-a ou o oposto, nós,

10 Tradução livre: "Trabalho com a intenção de refletir o que acontece no mundo ou, pelo menos, o que se sucede em meu contexto. Com cada ação, com cada projeto, desejo gerar um diálogo, questionar e também que o outro se questione. Me interessa investigar as relaçôes de poder em todas as suas manifestaçôes e, para isso, recorro à observação e à denúncia através de meu trabalho criativo e utilizo sempre um discurso simples, mas incisivo”. 
“os corpos associados", empaticamente nos sentimos presos àquela imagem, ao sofrimento, à aura mística que se cria em torno da performance e que impacta de maneiras bem singulares todos os envolvidos, mas sem deixar nunca de impactar (MERLEAU-PONTY, 2011, p. 127; MERLEAU-PONTY, 2013, p. 17).

Voltando ainda aos guatemalenses contemporâneos, os quais vivem as memórias da guerra civil atuando diretamente em suas próprias constituiçóes de habitantes da Guatemala, eles terão em mãos os elementos necessários para intuir o fundo existencial do qual falam as performances. Apesar disso, devemos compreender que não é fácil enfrentar os fatos postos por Galindo, ainda mais quando se têm, culturalmente, pouco contato com a arte performática e com a nudez artística. Nesse cenário, a possibilidade de Galindo performar sem maiores retaliaçóes em seu próprio país só aconteceu quando ela já estava consagrada fora dele. Mesmo nessa negação à arte visual de Galindo por parte dos guatemalenses, em toda a sua jornada como artista, foi a Guatemala que se mostrou como seu maior interesse, o lugar de onde faria brotar seus impulsos e suas motivaçóes.

Porém, o simples fato de ter abertura para performar náo significa que as performances deixaram de provocar incômodo ou estranhamento. Isso náo só pela já anunciada autenticidade de Galindo, mas também por seu estilo que nos coloca essa nudez da qual nós contemporâneos ignoramos como aspecto elementar do corpo. Certamente, o artista que usa da nudez em sua obra sabe, ou pelo menos intui, que há na nudez artística esta potência em atrair o olhar.

Não existe, na verdade, outro nu além daquele que se percebe nu. E grande é o paradoxo humano no qual não há humano que seja digno sem uma boa noção de si como nu e não há nada mais assustador à dignidade humana do que se perceber nu (BONDER, 1998, p. 11).

Somos nosso corpo, "contudo, esse corpo não cessa de nos surpreender e nos inquietar” (SANT’ANNA, 2005, p. 10) e a nudez é um dos aspectos corpóreos mais intrigantes, porém menos compreendidos. Ela, mesmo nos sendo essencial, tumultua nossos sentidos e emoçóes. A particularidade de modos de lidar com a nudez serão dados nas próprias circunstancialidades dos lugares. Em um simples exemplo, imagine-se retirando a roupa, isoladamente, no banheiro de sua casa para tomar banho e esse ato dificilmente se constituirá em problema. Fazemos isso cotidianamente, mas ao contrário, imaginando-se nu em meio à rua principal de sua cidade, perante outros, sabemos que dificilmente sairíamos dessa situação despercebidos.

Então, para compreendermos essas duas circunstancialidades, assim como tantas outras possíveis, é necessário compreender o lugar como um conceito que engloba "uma posição e uma situação que enfatiza o sentido relacional do ser-e-estar-no-mundo, ao mesmo tempo que dá o devido peso à realidade fenomênica do ser-aí e sua espacialidade". Ou seja, essa perspectiva nos permite pensar o lugar como dinâmico e referente "à mundialidade de nosso cotidiano", como detentor de elementos que o diferencia e o particulariza, mas, simultaneamente, interligado a outros lugares na espacialidade do mundo (MARANDOLA JR., 2014, pp. 230-232). 
Sendo o lugar tudo isso, Galindo pôde com êxito abarcar assuntos que não a atingem diretamente como guatemalense, mas como próprio ser-no-mundo. Na performance "Piedra" (Brasil12/2013), Galindo faz uma alusão ao sofrimento das crianças e das mulheres exploradas nas carvoarias brasileiras, nos atingindo certeiramente. Uma nova moralidade é constituída: nenhum corpo nu, até mesmo sendo urinado por um "estranho", é capaz de chocar mais do que a desumanização dessas pessoas. Coberta com esse carvão, um material tóxico, a artista mostra como em situaçóes de dor, o corpo pode se "petrificar" ao ser desumanizado. Ainda, mesmo que homens e mulheres tenham participado da performance com Galindo, é especialmente simbólico esses momentos em que homens vêm urinar nesse corpo feminino, pois podemos, com isso, remeter às diversas manifestaçóes das desigualdades de gênero. Galindo trabalha com um caso brasileiro e, nele, vê um problema da humanidade (GALINDO, 2014b).

\section{Figura 2 - "Piedra” (Foto de Julio Pantoja e Marlene Ramírez-Cancio)}

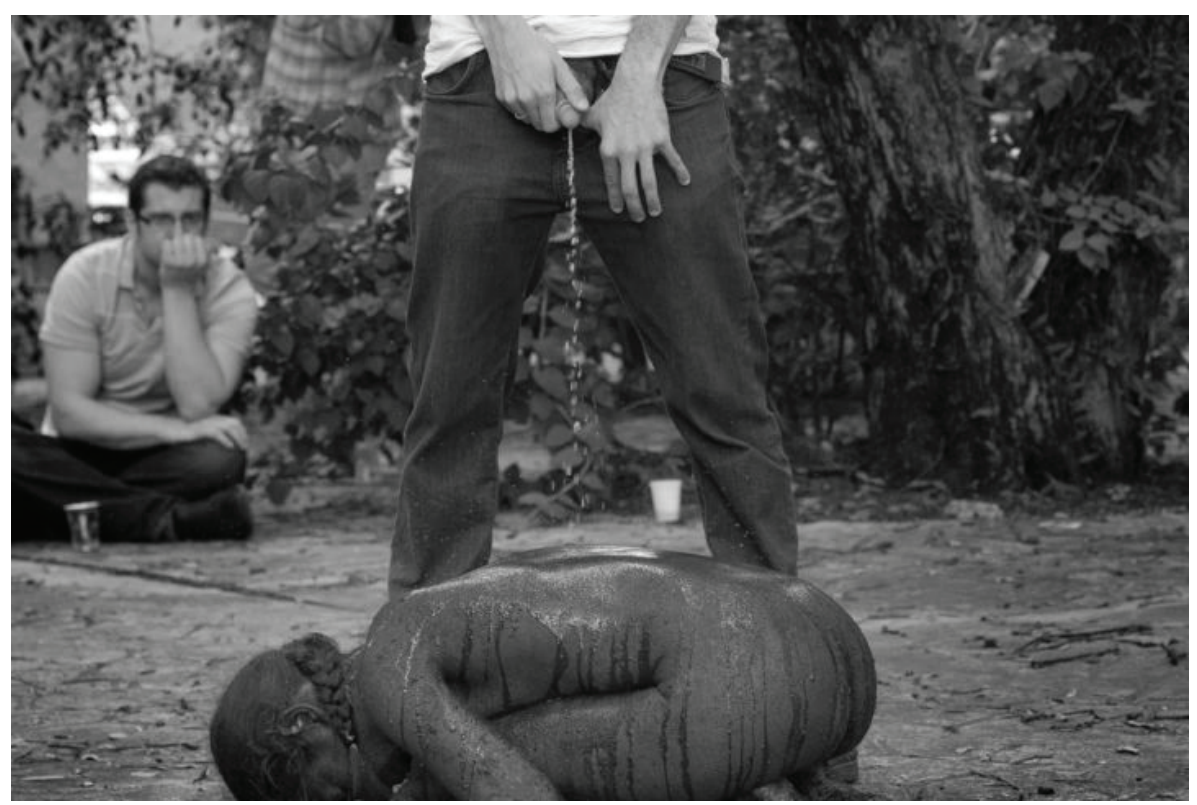

Fonte - Portfólio online da artista (2016)

"Piedra" remete à fragilidade que a nudez expressa em nossa contemporaneidade, onde ela adquire um status de desproteção do corpo. No entanto, Galindo, colocando seu corpo nu em situaçóes de dor e sofrimento, acaba por mostrar também força e resistência do corpo perante tais situaçóes, manifesta em forma de arte essa força vital essencial dos corpos sensíveis, presente mesmo nas situaçôes mais doloridas e desfavoráveis.

\footnotetext{
11 Tradução livre: "Pedra”.

12 Performance realizada para o $8^{\circ}$ Encontro do Instituto Hemisférico de Performance e Política, na Universidade Estadual de São Paulo (USP).
} 
Caminhando pelo mundo, Regina José Galindo viu a conectividade entre a Guatemala e os lugares estrangeiros através do sofrimento. $\mathrm{Na}$ sua obra, evidenciam-se as injustiças sociais cometidas em diversos países, inclusive com guatemalenses fora da Guatemala. É o que acontece em "America's family prison"13 (EUA/2008) e "Curso de supervivencia para hombres y mujeres que viajarán de manera ilegal a los Estados Unidos"14 (Guatemala/2007). Nessas performances, experiências de guatemalenses que buscam a vida nos Estados Unidos da América. Ao mesmo tempo que mostra a resiliência e a adaptaçáo dolorosa do guatemalense fora de seu país, idealiza-se a existência de um débito histórico dos norte-americanos para com os guatemalenses, onde há uma cobrança de posicionamento e reparação dos EUA frente ao fato da potência ter sido a maior provedora de armas para o exército guatemalense no período da guerra (GALINDO, 2014a, GALINDO, 2017).

\section{Figura 3 - "Mientras, ellos siguen libres" (Foto de David Pérez)}

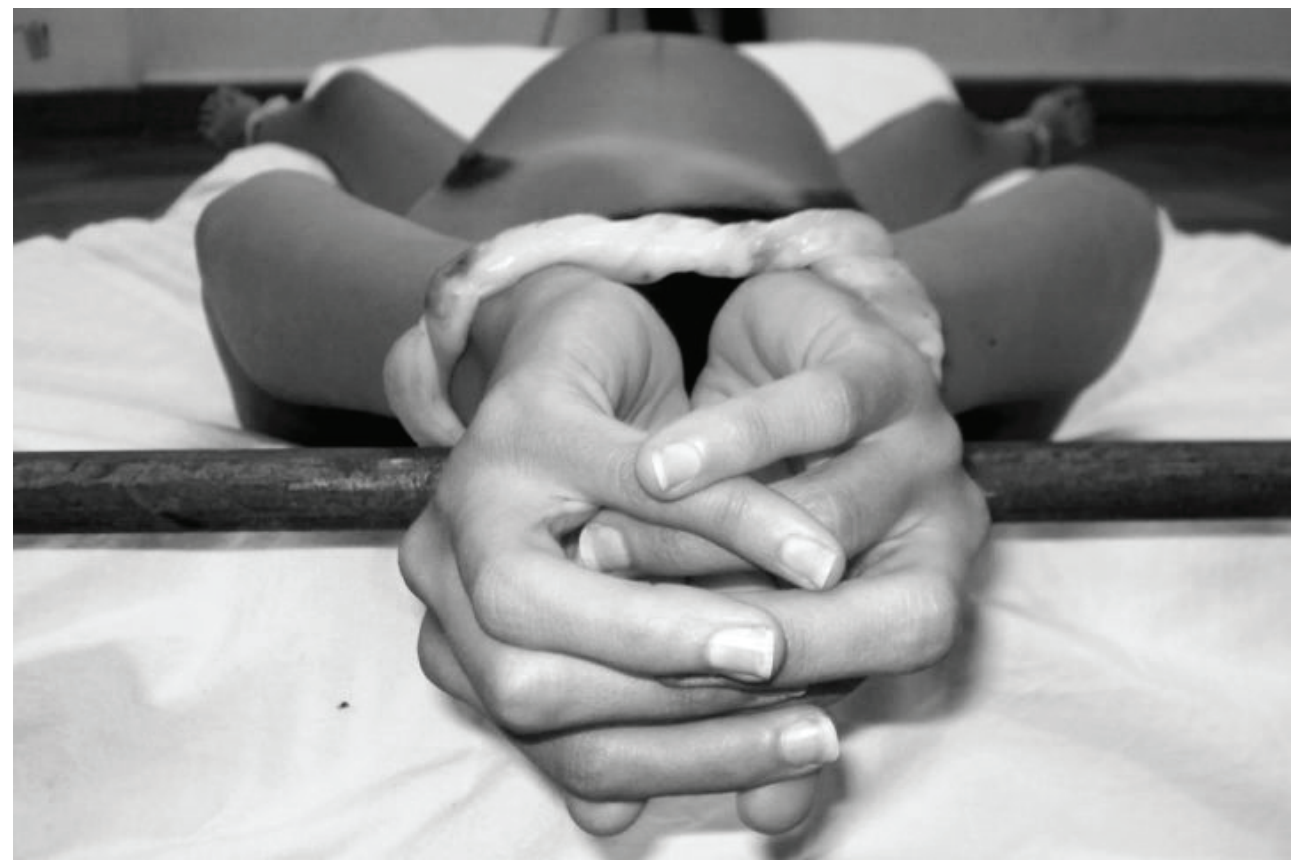

Fonte - Portfólio online da artista (2016)

Esta é uma revelação de que uma guerra civil não se limita ao território do país, nem acaba na data que fixamos no tempo cronológico. Ela se alastra, deixando medos e desentendimentos. Para os guatemalenses, a guerra mudou o modo deles lidarem com seu mundo e com os corpos femininos, marcou a miséria e o sofrimento na memória coletiva. Em sua

13 Tradução livre: "Prisão familiar da América". Para saber mais sobre o assunto ao qual Galindo se refere, indicamos, sobretudo, o curta de Matt Gossage \& Lily Keber intitulado “America's Family Prison” (2007), disponível em https://www.youtube.com/watch?v=c9Ub_9uQFk8.

14 Tradução livre: "Curso de sobrevivência para homens e mulheres que viajarão de maneira ilegal aos Estados Unidos da América”. 
performance mais emblemática sobre o assunto, "Mientras, ellos siguen libres"15 (Guatemala, 2007), Galindo coloca seu corpo feminino amarrado em uma maca por um cordão umbilical. Grávida, ela se mantém em silêncio com as pernas abertas. A performance é uma denúncia à impunidade dos abusos sexuais, físicos e psicológicos cometidos pelo exército contra as mulheres indígenas na guerra civil da Guatemala, o que configurou uma cultura do estupro perpassante até os dias de hoje (GALINDO, 2014b; GALINDO, 2017).

As mulheres violentadas, o sofrimento, a guerra, a dor e as injustiças sociais sempre foram temas nos quais Galindo se ocupou. Porém, seu trabalho não se reduz a esses temas, ele o extrapola ao abrir para o público a possibilidade de pensar além da violência e da opressão. Há um traço deixado pela própria artista, de onde emana uma faísca de força e resistência dos corpos femininos, dos corpos latinos, em suma, de todos corpos senciente-sensíveis (MERLEAU-PONTY, 2013, p. 21), mesmo que se encontrem em circunstâncias socialmente desfavoráveis. Ainda, é a nudez artística o fator mais expressivo dessa dualidade de fraqueza e resistência de um corpo, já que é ela o meio da artista nos colocar tanto a fragilidade do corpo tanto o quanto esse corpo, mesmo "desprotegido" (sem roupa) ainda sobrevive, nem que seja na desumanização, na petrificação, sendo ainda capaz de um dia se vestir de força (como em "Curso de supervivencia para hombres y mujeres que viajarán de manera ilegal a los Estados Unidos") e alterar o seu próprio devir. Essa é a potência de um corpo frente a um país, na verdade, é este o poder do corpo artístico, corpo que provoca, quebra barreiras e paradigmas e, na criação conjunta, faz pensar o mundo.

\section{CORPO MARCADO QUE MARCA}

Galindo é guatemalense e isso não se refere só ao lugar onde nasceu, mas à sua própria trajetória e experiência. Seu corpo possui marcas, é corpo latino-americano, é corpo feminino, cultural e histórico. A história da Guatemala é também sua. Como em qualquer corpo, a história vive integralmente em si. Parafraseando Merleau-Ponty, pela "ação da cultura", instalamo-nos em vidas que não são nossas, as confrontamos, revelamos "uma para outra", as tornamos "copossíveis numa ordem de verdade", nos tornamos responsáveis por todas, suscitamos "uma vida universal", assim como nos instalamos "de uma só vez no espaço pela presença viva e expressa” dos nossos corpos (MERLEAU-PONTY, 2013, pp. 83-109).

Todas as vezes que a artista performou Guatemala fora do país, só mostrou o quanto sua pátria tomou espaço como seu lugar, o quanto ela influi em sua vida, seu modo de pensar e suas ações, até mesmo as ações denunciativas. Existe, então, uma intersubjetividade que une todos os que habitam a Guatemala, um ser-no-mundo, uma essência expressiva que circunda todo um modo de viver a Guatemala, de se relacionar com ela, que transborda o indivíduo, porque não o limita. Essa essência é fluida, dinâmica e só existe na dependência de seus habitantes, o que permite que eles acessem experiências que não só as individuais, mas particulares do próprio lugar.

15 Tradução livre: "Enquanto eles seguem livres". 
Galindo, muito sensível à dor e ao sofrimento dos guatemalenses, encarnou nas obras suas convicçóes. Porém, ainda que ocultamente, nos mostra que um espaço tem que ter algo de seguro e acolhedor para ser lugar. Sendo assim, os habitantes da Guatemala carregam em si o que o lugar tem de pior e de melhor, criando, a partir disso, suas próprias resistências. Esse lugar também está encarnado no corpo de Galindo e é por isso que ela sempre se volta a ele. O corpo ao mesmo ponto que é "tocado", é "tocante" (MERLEAU-PONTY, 2013, p. 21), o que significa que não só a Guatemala age em Galindo, mas que o oposto é também verdadeiro. Desse modo, a importância de sua obra emerge quando a artista concretiza suas percepçôes, fazendo da nudez artística o meio mais poderoso de criação de novos sentidos, apontando caminhos distintos para as relaçóes humanas, sendo arte no mundo, uma potência criativa autêntica e emancipadora em si. 


\section{REFERÊNCIAS BIBLIOGRÁFICAS}

BACHELARD, Gaston. A poética do devaneio. Sáo Paulo: Martins Fontes, 2009.

BONDER, N. A alma imoral: traição e tradição através dos tempos. Rio de Janeiro: Rocco, 1998.

CASALINI, Giulia. Incorporaçôes feministas do silêncio: a performance do discurso intolerável no trabalho de Regina José Galindo. Ex aequo, n. 27, pp. 27-41, 2013.

FERNANDES, Sílvia. Teatralidade e performatividade na cena contemporânea. Repertório, Salvador, Universidade Federal da Bahia, n. 16, pp. 11-23, 2011.

GALINDO, Regina José. La obra literaria de Regina José Galindo. Asparkía: investigació feminista, n. 24. Universitat Jaume, pp. 205-219, 2013.

- LASS Interview Regina Jose Galindo. LACAP. TOLEDO, Tamara, RIDDIHOUGH, Peter. Toronto, 2014a. Disponível em: https:/www.youtube.com/watch?v=9QVOWF86Y0o. Acessado em: março de 2017.

. Conversación: Regina José Galindo y Emiliano Valdés. Gasworks, Londres, 2014b. Disponível em: https://www.youtube.com/watch?v=CWte8nH3jGQ. Acessado em: março de 2017. ço de 2017.

Portfólio. Disponível em: http://www.reginajosegalindo.com/. Acessado em: marGROSSAGE, Matt, KEBER, Lily. America’s Family Prison. 2007. Disponível em: https:// www.youtube.com/watch?v=c9Ub_9uQFk8. Acessado em: março de 2017.

HEIDEGGER, Martin. A origem da obra de arte. In: Caminhos de floresta. Lisboa: Instituto Gulbenkian, 2012.

LEFORT, Claude. Prefácio. In: MERLEAU-PONTY, Maurice. O olho e o espírito. Cosac Naify Portátil. São Paulo: Cosac Naify, 2013. pp. 9-14.

MARANDOLA JR., Eduardo. Lugar Enquanto Circunstancialidade. In: MARANDOLA JUNIOR, Eduardo; HOLZER, Werther; OLIVEIRA, Livia de (org.). Qual o espaço do lugar?: geografia, epistemologia, fenomenologia. São Paulo, SP: Perspectiva. 2014. pp. 227-248.

Mapeando "londrinas": imaginário e experiência urbana. Geografia (Rio Claro), Rio Claro, SP, v.33, n.1 ,pp.103-126, 2008.

MERLEAU-PONTY, Maurice. A prosa do mundo. Cosac Naify Portátil. São Paulo: Cosac Naify, 2014.

. Fenomenologia da percepção. São Paulo: WSF Martins Fontes, 2011.

. O olho e o espírito. Cosac Naify Portátil. São Paulo: Cosac Naify, 2013.

. O visível e o invisível. São Paulo: Perspectiva, 2007. 
OLIVEIRA, Lívia de. O Sentido de lugar. In: MARANDOLA JR., Eduardo; HOLZER, Werther; (org.). Qual o espaço do lugar?: geografia, epistemologia, fenomenologia. São Paulo, SP: Perspectiva, pp. 3-16, 2014.

SANT'ANNA, Denise. Prefácio à segunda edição. In: SANT’ANNA, Denise Bernuzzi de (org.).

Políticas do corpo: elementos para uma história das práticas corporais. São Paulo, SP: Estação Liberdade, pp. 9-10, 2005.

SANTOS, José Mário Peixoto. Breve histórico da "performance art" no Brasil e no mundo. Ohun, v. 4, n. 4, pp. 1-32, 2008.

SCHAMA, Simon. O poder da arte. Trad. Hildegard Feist. São Paulo: Cia. das Letras, 2010.

Recebido em junho de 2017. Aprovado em dezembro de 2017. 